\title{
LÉXICO Y LEXICOGRAFÍA DEL ESPAÑOL DE COSTA RICA EN LA VISIÓN DEL DR. VÍCTOR ML. SÁNCHEZ CORRALES
}

\author{
Mario Hernández Delgado
}

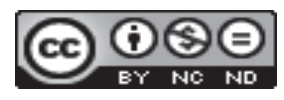

Esta obra está bajo una licencia Creative Commons Reconocimiento-No Comercial-Sin Obra Derivada 



\title{
LÉXICO Y LEXICOGRAFÍA DEL ESPAÑOL DE COSTA RICA EN LA VISIÓN DEL DR. VÍCTOR ML. SÁNCHEZ CORRALES
}

\author{
LEXICON AND LEXICOGRAPHY OF COSTA RICAN SPANISH \\ ACCORDING TO DR. VÍCTOR ML. SÁNCHEZ CORRALES
}

Mario Hernández Delgado

\begin{abstract}
RESUMEN
El objetivo del presente trabajo es exponer, a manera de esbozo, las ideas que forman el soporte conceptual básico del pensamiento del lingüista costarricense Víctor Ml. Sánchez Corrales para la descripción y análisis de los factores históricos, culturales e intelectuales que han dado y dan especificidad al léxico y a la lexicografía del español de Costa Rica.

Palabras clave: español de Costa Rica, léxico costarricense, lexicografía costarricense, identidad lingüística, Sánchez Corrales-Víctor M1.
\end{abstract}

\begin{abstract}
The purpose of this paper is to set out, as an outline, the ideas that constitute the basic conceptual support of the Costa Rican linguist Víctor M1. Sánchez Corrales' thought for describing and analysing historical, cultural and intellectual factors that have given and give specificity to the lexicon and lexicography of Costa Rican Spanish.

Key words: Costa Rican Spanish, Costa Rican lexicon, Costa Rican lexicography, linguistic identity, Sánchez Corrales-Víctor Ml.
\end{abstract}

\section{Introducción}

El texto que sigue tiene como base el que se preparó para ser leído en el marco de la Segunda Semana de la Diversidad Lingüística de Costa Rica (noviembre de 2013), ${ }^{1}$ concretamente en la mesa-conversatorio sobre la labor académica e investigativa del Dr. Víctor Ml. Sánchez Corrales, dedicado de la actividad. Su intención es exponer una síntesis de las ideas fundamentales de este destacado lingüista costarricense con respecto, tanto al carácter del componente léxico del español de Costa Rica, como al proceso de consolidación de una lexicografía costarricense; al mismo tiempo, se establecen los conceptos teórico-metodológicos fundamentales sobre los que se asienta su perspectiva de análisis.

M.L. Mario Hernández Delgado. Universidad de Costa Rica. Programa Estudios de Lexicografía (ELEXHICÓS), adscrito al Instituto de Investigaciones Lingüísticas. Universidad de Costa Rica. Costa Rica

Correo electrónico: mario.hernandez@ucr.ac.cr

Recepción: 10- 03- 2014

Aceptación: 18- 03- 2014 
Antes de entrar en materia, quisiera manifestar al Dr. Carlos Sánchez mi agradecimiento por la invitación a redactar un aporte para el conversatorio sobre la obra de don Víctor Ml. Sánchez Corrales, así como mi felicitación por el interés que han logrado sus dos Semanas de la Diversidad Lingüística en el ámbito universitario y nacional.

En cuanto al Dr. Sánchez Corrales, comenzaré por decir que, aun cuando es capaz de moverse con igual rigor y erudición por los más diversos terrenos de la lingüística, la vida, o, mejor dicho, ese conjunto de hechos y eventos (desde los más cotidianos hasta los más trascendentales) que van dando forma a lo que cada uno de nosotros llega a ser, a sentir, a pensar y a hacer, ha moldeado su vocación de modo que su actividad tuviera ciertos campos preferidos para sembrar. Lo que voy a exponer está centrado en dos de esos campos escogidos por su vocación, ambos, como es claro, íntimamente relacionados: léxico y lexicografía, concretamente los del español de Costa Rica. De ellos, y su relación, intentaremos reseñar los conceptos pivotales de la concepción del productivo investigador.

Ahora bien, ante la tarea de hacer un recuento de las ideas de un autor, posiblemente nadie la podría llevar a cabo mejor que el autor mismo, pues es él quien ha visto "desde dentro" cómo se han ido sumando los pensamientos, los conocimientos, las intuiciones y, por qué no, incluso las pasiones intelectuales, hasta ver surgir, a partir de todos esos elementos, aquellos chispazos de síntesis que se reflejan en los diversos momentos del devenir de su obra.

Con esta consideración, visto quien esto escribe ante el reto de intentar presentar las líneas esenciales del pensamiento de don Víctor sobre el tema ya señalado, no podría esperar exponer más que un esbozo muy general y simplificado de lo que se encuentra en sus textos. Subyace, además, en esta labor, la esperanza de que el autor del que proceden esas ideas encuentre acertada la lectura que se hace aquí de sus planteamientos.

Con base en el análisis de sus artículos y otras contribuciones en compilaciones y encuentros académicos, y con constante apoyo en citas extraídas de esos textos, se muestra que el concepto de experiencia de vida tiene no solo un estatus axial en su concepción del proceso de conformación del léxico del español de Costa Rica, visto como conjunto, sino también que está, para él, en la base de la justificación de cualquier actividad lexicográfica. Complementariamente, se expone de forma muy resumida su visión del camino recorrido por la lexicografía costarricense con especial referencia a las tendencias y actitudes paradigmáticas dominantes en contextos temporales y geográficos más amplios.

\section{Experiencia de vida como categoría teórica básica}

El punto de partida de esta exposición será la noción de experiencia de vida, concepto constante en los artículos del profesor Víctor Sánchez de los últimos lustros, casi al punto de constituirse en una especie de firma en sus textos.

Lejos de ser meramente un recurso para agregar connotaciones emotivas, dramáticas o literarias a sus explicaciones, el concepto de experiencia de vida parece tener para el autor más bien el estatuto de una categoría teórica fundamental para dar razón del origen de las motivaciones por las que una comunidad va construyendo todos aquellos elementos culturales, tanto materiales como intelectuales, que la identifican y con los que ella se identifica.

En realidad, en el concepto de experiencia de vida podemos reconocer dos aristas complementarias. En un sentido más bien primario, se puede entender como el conjunto de contingencias que ocurren o por las que transcurre la existencia de un ser individual o colectivo, siempre que estas contingencias: a) sean relevantes para la pervivencia y adaptación 
de tal individuo o colectividad al medio en que se debe desenvolver, y b) se integren de manera significativa, esto es, relevante, en la memoria individual o colectiva (respectivamente).

Por otro lado, el concepto de experiencia de vida se puede entender también como una noción de carácter teórico-metodológico que se muestra útil para explicar las especificidades culturales (complementariamente con las sociales, políticas, morales, estéticas, etc.) de una comunidad humana.

En todo caso, la experiencia de vida de una colectividad, en cuanto que fuente motivadora de la concepción de mundo particular del conjunto de sus miembros, se ve reflejada y objetivizada en múltiples signos externos producidos por la actividad social: estilos arquitectónicos, costumbres, preferencias culinarias, etc., sin olvidar, por supuesto, la lengua en sus diferentes componentes.

\title{
3. El componente léxico
}

En particular, y de un modo que reviste especial relevancia para los propósitos de la comunicación lingüística, el componente léxico de una lengua, visto como un todo, se ve continuamente moldeado, adaptado y reacomodado a las nuevas realidades a las que se enfrenta el grupo social. En palabras del autor:

\begin{abstract}
El léxico, por su dependencia del fluir de la vida material y espiritual, se modifica de una manera más profunda y fácil que los otros niveles de la lengua.

Este hecho vale también para variedades lingüísticas de una misma lengua. Así las cosas, el español en Costa Rica, además de un patrimonio léxico común con las otras variedades del español peninsular o americano, tendrá un número significativo de palabras que lo diferencian de otras hablas hispanoamericanas o peninsulares, en virtud de la experiencia costarricense ante la vida.

El léxico del español de Costa Rica, en este sentido, refleja la experiencia existencial que tienen los costarricenses acerca de la vida, de la naturaleza, de sus percepciones, de los objetos y animales que los rodean, de sus emociones, de sus conocimientos y creencias, de las comidas, de la siembra y la cosecha, de las costumbres, de las esperanzas, del trabajo y de sus juegos, etc. Constituye, por tal razón, un componente abierto y en evolución al unísono con el decurso de la vida costarricense y la formación de una conciencia nacional: en él están la memoria, la conciencia y la esperanza de los hablantes del español como lengua materna, que habitan la República de Costa Rica. (Sánchez-Corrales, 2011, p. 84).
\end{abstract}

Ahora bien, el contexto más primario y general en el que se enmarca la experiencia de vida de una comunidad humana está constituido por las condiciones históricas y geográficas particulares en que ha tocado a sus miembros desenvolverse desde generaciones atrás. Todo ese entramado de circunstancias sociales, culturales, temporales y geográficas deja huellas en la conciencia lingüística de un pueblo, en particular el costarricense. De este modo,

[...] al estudiar la génesis del español americano como modalidad de lengua que empieza a diferenciarse del modelo peninsular español, en ella misma comienza a configurarse el mapa dialectal del español americano. (Sánchez-Corrales, 1998b, p. 109).

Según explica el autor, cuando comienza el período de conquista y colonización de lo que posteriormente llegaría a ser Costa Rica, había en la zona una variedad de agrupaciones aborígenes, diversas tanto en lo tocante a su filiación cultural como a su procedencia ambiental y geo-agronómica:

a. Cultura del bosque tropical seco del Pacífico Norte, de tradición mesoamericana.

b. Cultura del bosque tropical húmedo del Pacífico Sur, de tradición suramericana subandina.

c. Cultura del bosque húmedo tropical del Atlántico, vinculada con la tradición suramericana de las selvas tropicales amazónicas. 
Por otro lado, en el momento de los primeros asentamientos de españoles en nuestros suelos, habían ya transcurrido 69 años desde el primer encuentro de culturas en las Antillas Mayores, y durante ese tiempo se habían fundado ciudades en el norte y sur del "Nuevo Continente". Los españoles que se dedicaron al poblamiento de los futuros territorios costarricenses procedían, al igual que en el resto de América, de diferentes zonas dialectales de la Península, además de que eran usuarios de dialectos y registros también diversos. Pero también vinieron a Costa Rica, y en cantidad no despreciable, españoles nacidos ya en tierras americanas, que procedían a hacer migraciones intercontinentales llevados por el espíritu de aventura o por el afán de hallar mejores condiciones para asentarse.

En cuanto a esta compleja situación, y sus consecuencias para la conformación del español costarricense, comenta, don Víctor Sánchez, lo siguiente:

\footnotetext{
Las anteriores circunstancias favorecieron el que a Costa Rica llegara una lengua con casi setenta años de asentamiento y expansión en América, un español americanizado, variedad ya usada por los españoles nacidos en América, además de usos lingüísticos varios correspondientes a los españoles que venían directamente de la Península. De este modo a la diversidad del elemento español debe agregársele un contorno cultural vario que enriquece la interacción y, con el fluir de la historia, le va forjando la fisonomía al español hablado en Costa Rica. (Sánchez-Corrales, 1998b, p. 112).
}

Aparte de los elementos de origen patrimonial e indígena, el autor identifica otras procedencias que han dejado huella en el constituyente léxico del español de Costa Rica, aportando todos ellos elementos que en diversos grados han llevado a esculpir su perfil. Estas son, en síntesis, las clases de elementos diaintegrativos que el autor reseñado reconoce en el léxico del español de nuestra región:

a. el léxico patrimonial español, procedente de diversas hablas regionales y sociolectales de la Península;

b. el elemento indoamericano aportado al español de América por diversas lenguas indígenas del continente durante la conquista y colonia (nahuatlismos, voces arahuacocaribes, quechuismos), además del de procedencia indocostarricense;

c. el elemento africano, que nos llega, ya sea integrado en el español tardío americanizado de los primeros colonizadores, o ya sea por la llegada de esclavos africanos, especialmente en el Caribe insular y costas caribeñas continentales;

d. el elemento xenista, particularmente galicismos y anglicismos; y, finalmente,

e. el elemento que llega como préstamo léxico proveniente de otra variedad del español americano, merced a factores como la proximidad geográfica, interacción social, hegemonía cultural u otras razones.

\section{El proyecto lexicográfico costarricense}

En estrecha relación con su interés por el estudio del léxico del español costarricense desde una perspectiva dialectológica (y, en términos más amplios, sociolingüística), el profesor Sánchez Corrales ha dedicado buena parte de sus esfuerzos como investigador y como formador precisamente a la disciplina que se encarga de recolectar y describir con sistematicidad los usos, sentidos y significados de las palabras; es decir, a la lexicografía. 
Sus estudios críticos sobre la obra de los maestros fundadores y continuadores de la lexicografía costarricense constituyen materiales de consulta indispensables para cualquiera que desee visualizar, con amplia perspectiva, el camino recorrido por esta disciplina en el ámbito geográfico de nuestra nación. ${ }^{2}$ Sin embargo, aquí nos detendremos únicamente en los elementos que permiten contextualizar el desarrollo de la labor lexicográfica costarricense de manera global. Lo que sigue intenta resumir, en la medida de lo posible, las bases teóricas e históricas sobre las que se asienta el pensamiento del autor, extraídas de sus textos a veces con poca reformulación, y en no pocas ocasiones citando directamente sus propias palabras.

La tradición lingüística en Costa Rica hasta la década de los años setenta del siglo $\mathrm{XX}$, tanto en lo tocante a los estudios especializados como a la planificación de la enseñanza del español en los diferentes niveles educativos, estuvo caracterizada por la influencia decisiva de la doctrina gramatical de la Real Academia Española y de los planteamientos teóricos de Andrés Bello. En ambos casos, la gramática es concebida como arte, con la única diferencia de que Bello promueve la modalidad lingüística culta americana como criterio de corrección idiomática para las hablas hispanoamericanas. En concordancia con ese paradigma, dominante tanto en el ámbito de las políticas curriculares como en el de la descripción sistemática de nuestro vocabulario diferencial, la mayoría de los estudios escritos hasta esa década son preceptivos. En otras palabras, durante toda esa etapa se consideró la variación dialectal, en la medida en que discrepa y se separa del uso culto, como un fenómeno sociolingüístico que menoscaba la pureza y corrección de la lengua castellana (cf. Sánchez-Corrales, 1988a, p. 147).

Tal influencia de la doctrina académica y, con la diferencia señalada, de la doctrina bellista, no ha favorecido los estudios dialectales del español en Costa Rica, pues toda descripción que se asiente sobre esos principios doctrinales de actitud purista considerará las variedades locales, y en particular la variedad del español en Costa Rica, en la medida en que transgreden la norma de prestigio, como corruptelas, incorrecciones, barbarismos, vicios del lenguaje, lenguaje avulgarado o de segunda categoría.

Para comprender la historia y los retos de la lexicografía del español en América, y en particular los del español de Costa Rica, hay que tomar en cuenta, según el profesor Sánchez, tres elementos fundamentales: a) el fenómeno socioliongüístico de extensión de lengua, b) la construcción de identidades nacionales en los países hispanohablantes de América y c) la concepción de la lengua como diasistema.

\subsection{Extensión de lengua}

La lexicografía del español costarricense ha seguido la misma trayectoria que en el resto de los países hispanoamericanos, así como la de los estudios sobre el español americano en general. Ha sido la trayectoria marcada por el fenómeno conocido como extensión de lengua, característico de los procesos históricos de expansión geopolítica de un imperio.

En un primer momento, la extensión de lengua se manifiesta por medio de una política colonial de unificación de la lengua como estrategia de hegemonía en torno a un centro imperial de influencia cultural, en aras de la continuidad y fortalecimiento de la monarquía. En el caso del español americano, el centro de referencia es el español cortesano peninsular, en un inicio el toledado, aunque luego el madrileño. Como consecuencia de esa actitud oficial, las variedades locales divergentes se consideran como formas adulteradas, impuras y defectuosas. Esta política domina todo el período colonial hispanoamericano y se proyecta hasta el siglo XX, según el grado de identidad e independencia de las naciones. En palabras del autor: 


\begin{abstract}
El español de América y con ello su diferenciación léxica, en sus orígenes mismos, nace bajo el estigma de ser menos puro y elegante que el español de España, se concibe como una variedad periférica de ese y sus peculiaridades diatópicas no son dignas de entrar en la lengua ejemplar. Esta valoración de los usos lingüísticos americanos, compartida en uno y otro lado del Atlántico, constituye un criterio fundamental de selección de la nomenclatura de los primeros tratados lexicográficos sobre el español costarricense y el americano en general. (Sánchez Corrales, 2001, p. 12).
\end{abstract}

La segunda etapa de la internacionalización del español se da como consecuencia de los procesos independentistas que llevan al surgimiento de nuevas naciones, cada una de las cuales, ya escindida del imperio original, mantiene el español como lengua oficial, reconociéndolo como parte de su patrimonio y su identidad. Ante el hecho incuestionable del surgimiento de particularidades locales en el uso de la lengua española, la reacción de los hispanoamericanos fue mantener la pureza y unidad de esta. Para este propósito, y muy a tono con el espíritu cultural heredado de la época colonial respecto de las políticas lingüísticas, se toma como referencia el español castellano, consignado, para efectos de servir como modelo, en las obras de la Real Academia Española, cuya creación (1713) concreta la institucionalización de los procedimientos coloniales unificatorios en materia de lengua. En la lexicografía costarricense, el exponente por excelencia de esta actitud es el Gagini de 1892, con su Diccionario de barbarismos y provincialismos de Costa Rica.

La tercera etapa del proceso de extensión de lengua, aplicado al español americano y al costarricense en particular, tiene también a Gagini, pero esta vez al de 1918, como exponente. En claro paralelismo con Cuervo en lo que respecta al español americano, Gagini desecha en su nuevo diccionario la idea de que la variación léxica del español de Costa Rica implica corrupción y deformación respecto de la lengua ejemplar. A pesar de que en diversos teóricos subsiste, en diferentes grados o matices, la idea de tomar como nuevo modelo un español culto americano, ya se le da estatus de existencia científica al léxico "real", es decir, al efectivamente utilizado por los pueblos para efectos comunicativos. Esta nueva actitud deja de lado el eurocentrismo anterior y reconoce en el conjunto de las diversas formas del español, como lengua de muchas naciones, un policentrismo lingüístico.

De este modo, conforme avanza el siglo XX, el registro, estudio y enseñanza de la lengua se ven cada vez más beneficiados de una nueva concepción del español como un caso de convergencia lingüística, aspecto que se refleja en el interés de que las políticas lingüísticas se nutran de teorías y metodologías científicas de avanzada para el tratamiento lexicográfico, descriptivo y pedagógico del léxico. En este sentido, el autor indica que:

\footnotetext{
Este cambio paradigmático en las políticas lingüísticas de la Academia, obedece al desarrollo de la lingüística como ciencia y, en cuanto a los diccionarios, al surgimiento de una metalexicografía científicamente sustentada. El diccionario es un constructo social, sirve de depósito de la experiencia de vida de una comunidad de habla y con ella, por medio del significado de la palabra cristalizada bajo una determinada forma de texto escrito - un libro-, se manifiesta su identidad para que perdure su pasado y construya su presente. (Sánchez-Corrales, 2001, p. 16).
}

Es en ese contexto actitudinal en el que surgen en nuestro país el Diccionario de costarriqueñismos de Agüero (1996) y las diferentes ediciones del Nuevo diccionario de costarriqueñismos de Quesada Pacheco (1991 y 1996, a la fecha en que el Dr. Sánchez Corrales escribe el artículo de 2001). Es también la actitud para el tratamiento y registro científico del léxico que adoptan los diversos trabajos producidos por el programa y línea de investigación ELEXHICÓS, bajo el impulso de don Víctor Sánchez como gestor y coordinador. 


\subsection{Lengua como diasistema}

Otro concepto infaltable en los ensayos de don Víctor Sánchez en torno a los retos de la lexicográfica costarricense es el de la lengua considerada como diasistema. En primer lugar, tal como se ha visto, la concepción de la lengua española como diasistema está en la base de la justificación de la coexistencia de diversas variedades locales de nuestra lengua común, sin necesidad de afirmar la preeminencia de una variedad sobre otras. Esta concepción diasistemática sería, en otras palabras, la base de la convivencia lingüística y la tolerancia.

En segundo lugar, es también elemento central del pensamiento lexicográfico del Dr. Sánchez Corrales que las investigaciones lexicográficas costarricenses deben reflejar adecuadamente en sus obras (los diccionarios de lengua diferenciales-contrastivos) la diversidad de usos de los vocablos según factores geográficos, socioculturales y pragmáticos, pues esta variedad de niveles y de usos representa la dinámica real de la lengua. Además de que ese proceder es el único coherente con una actitud verdaderamente científica para la investigación y descripción de la lengua, es el más consistente con el carácter pedagógico del diccionario. En palabras del autor:

\footnotetext{
La lengua como un bello, puro y pulcro sistema homogéneo de reglas, obtenido a partir del uso lingüístico culto, peninsular, especialmente del texto literario escrito, modelo ideal de enseñanza en la escuela costarricense como paradigma de corrección idiomática (ejemplo, Gagini 1904a: II), debe ceder su lugar a lo que es por naturaleza: diversidad de usos, variedades según factores geográficos, socioculturales y estilísticos. En otras palabras, el modelo académico, en esencia saussureano, debe ser sustituido por el modelo sociolingüístico de lengua y la noción de corrección idiomática debe reemplazarse por el concepto de adecuación comunicativa, la cual se constituye en una nueva preceptiva, no ya ancha y ajena, que se fundamenta históricamente en la interacción comunicativa, es decir, la norma es una categoría lingüístico-social basada en la competencia comunicativa (Hymes 1972) y que se obtiene mediante la investigación constante de aquella [...]. (Sánchez-Corrales, 1991, p. 1215).
}

\subsection{Identidad nacional}

La experiencia de vida constituye, según lo que se ha mencionado, una fuente de conocimientos a la vez comunitarios e irrepetibles, lo que explica no solo la singularidad de la estructuración social y cultural de cada comunidad humana, sino también la singularidad de la concepción que la propia comunidad de habla tiene de su pasado, de su presente y aun de su porvenir, concepción que representa un elemento indispensable de la autopercepción de su identidad. Como dice don Víctor:

\footnotetext{
La visión del mundo es un constructo social. La experiencia de vida del hombre, en tanto miembro de una comunidad de habla, se construye por su interacción comunitaria, en especial mediante el lenguaje articulado gracias a la naturaleza de "zoon logicón" y de "zoon politicón" del ser humano en sociedad. Se rechazan antivalores, se comparten valores, costumbres, hábitos de alimentación, formas de vestir, tipos de diversiones, etc., lo cual conlleva a la toma de conciencia de la mismidad, de ese "algo" que nos diferencia de otros, de los extraños. (Sánchez Corrales, 2009, p. 34).
}

La autopercepción identitaria de una comunidad no queda, sin embargo, restringida al ámbito de lo inmaterial (valores, actitudes, sentimientos) ni de lo individual, sino que se ve objetivizada e intersubjetivizada por medio de especificidades culturales y lingüísticas que la comunidad reconoce como exponentes perceptibles de su identidad y de sus sistemas de conocimiento y creencia. En particular, las peculiaridades léxicas de una colectividad históricamente consolidada cuya lengua materna es el español representan, ya por sí mismas, un rasgo diferenciador respecto de otras comunidades que también tienen la lengua española como medio de cohesión y comunicación. 
Es la suma de todos esos elementos la que, en el caso de la región geográfica conocida como Costa Rica y de la gente que la habita, permite hablar de una "costarriqueñidad", la cual el autor caracteriza de la siguiente manera:

\begin{abstract}
Entiendo por costarriqueñidad un proceso subjetivo, constructor, dinámico de delimitación simbólica de los contornos de la comunidad que se autodenomina costarricense y que también es reconocida por otras comunidades como costarricense. Esta comunidad se acredita y se le acreditan una serie de atributos, en principio diferenciadores, considerados como propios, tanto por ella como por otra distinta: espacio geográfico, sistema educativo, hábitos, formas de pensamiento, organización social, distribución de los poderes, integración de la familia, valores, etc. Esos atributos cumplen una función trascendental como criterio diferenciador y contrastivo de la comunidad costarricense respecto de otros grupos humanos. Crean conciencia de grupo, sentido de pertenencia y mismidad, cohesión en sus miembros, autorreconocimiento frente a los otros y heterorreconocimiento respecto del nosotros. La costarriqueñidad constituye un texto social, histórico, por lo tanto implica creaciones, recreaciones y sustituciones, usos, desusos, obsolescencias y muerte, ocultamientos y relieves. Nuestra variedad de lengua española, como lengua oficial, constituye uno de los atributos dinámicos que contribuyen a construir nuestra costarriqueñidad. Y hago la aclaración del español como lengua oficial, porque Costa Rica es plurilingüe, pluricultural y pluriétnica. (Sánchez-Corrales, 2010, pp. 176-77).
\end{abstract}

\title{
5. Conclusión
}

A modo de conclusión, me permitiré solamente recordar algunas de las palabras expresadas por don Víctor Sánchez en el discurso ofrecido con ocasión de la inauguración del II Coloquio Costarricense de Lexicografía (2003), en las cuales podemos captar lo que considero una síntesis de todo lo expuesto en las líneas precedentes en relación con su pensamiento sobre el carácter del léxico y la lexicografía del español de Costa Rica:

No hay lexicografía sin una aprehensión de la experiencia de la vida de los pueblos, cristalizada en la palabra como tesoro de su memoria, conciencia y esperanza. Porque la tarea del lexicógrafo es fundamental en este proceso de autoencuentro de identidades, de reconocimiento de la otredad, de diálogo de culturas como condición sine qua non de una vida plena, sustentada en el desarrollo humano. (SánchezCorrales, 2003, p. 10).

\section{Notas}

1. Al texto original únicamente se le han realizado las modificaciones pertinentes para su publicación en estas memorias, las cuales básicamente tienen que ver con adecuaciones de índole estilística, algunos cambios en el orden relativo en que se exponen determinadas partes y los ajustes formales necesarios para ceñirse a las convenciones de la Revista.

2. Sus análisis pueden ser consultados, por ejemplo, en Sánchez Corrales (1988a, 1993, 1996, 2001, 2006a, 2007, 2008), entre otros.

\section{Bibliografía}

Albalá, M.J. et ál. (Eds.). (2006). Filología y Lingüística, Estudios ofrecidos a Antonio Quilis. Madrid: Ministerio de Educación y Ciencia, Consejo Superior de Investigaciones Científicas, UNED y Universidad de Valladolid.

Gagini, C. (2008). Diccionario de costarriqueñismos. (4 ed.). San José: Editorial Costa Rica.

Sánchez-Corrales, V.M. (1987). Dialectología costarricense: visión crítica. Segundo Congreso Nacional de Filología y Lingüística. Universidad Nacional de Costa Rica. Letras. (1516-17), 123-131. 
Sánchez-Corrales, V.M. (1988a). Lexicografía del español en Costa Rica: visión crítica. Revista de Filología y Lingüística de la Universidad de Costa Rica. 14 (2), 147-156. [Edición en memoria del Primer Coloquio Germano-hispanoamericano de Lexicografía del Español de América. Instituto Caro y Cuervo].

Sánchez-Corrales, V.M. (1988b). Concho, ¿hipocorístico, quechuismo o término peninsular? Káñina. 17 (2), 113-116.

Sánchez-Corrales, V.M. (1991). Lengua española en la educación costarricense. Redefinición. Por C. Hernández et ál. (Eds.). III Congreso Internacional de "El español de América”. Valladolid-España, 3-8 de julio de 1989. (1211-1218).

Sánchez-Corrales, V.M. (1993). El legado lingüístico de Aturo Agüero Chaves. Por Y. SolanoRojas (Comp.). Memoria del V Congreso de Filología Y Lingüística Arturo Agüero Chaves. Universidad de Costa Rica. (39-42).

Sánchez-Corrales, V.M. (1996). La tarea lexicográfica y proyectos de investigación. Káñina. 20 (2), 111-117.

Sánchez-Corrales, V.M. (1998a). Léxico básico de los preescolares costarricenses, elementos diaintegrativos. Educación. 22 (2), 45-51.

Sánchez-Corrales, V.M. (1998b). Nuevo Diccionario del Español de Costa Rica. Elementos léxicos constitutivos peninsulares-europeos. Káñina. 22 (3), 109-121.

Sánchez-Corrales, V.M. (2000). Eufemismos en el español de Costa Rica. Káñina. 23 (3), 133 141.

Sánchez-Corrales, V.M. (2001). La lexicografía hispánica en Costa Rica. Los diccionarios de lengua. Káñina. 25 (2), 11-20.

Sánchez-Corrales, V.M. (2003). Discurso inaugural. Kañina. 29 (Especial), 9-10. [Edición en memoria del II Coloquio Costarricense de Lexicografía. Universidad de Costa Rica].

Sánchez-Corrales, V.M. (2006a). Dimensión léxica del español de América. Estudios lexicográficos diferenciales en el español de Costa Rica. Por Albalá et ál. (Eds.). Filología y lingüística, Estudios ofrecidos a Antonio Quilis. (813-835). Madrid: Ministerio de Educación y Ciencia, Consejo Superior de Investigaciones Científicas, UNED y Universidad de Valladolid.

Sánchez-Corrales, V.M. (2006b). Léxico relativo al ámbito del tamal en Costa Rica. Káñina. 30 (2), 191-197.

Sánchez-Corrales, V.M. (2007). Sincronía y contrastividad en la obra lexicográfica de D. Arturo Agüero Chaves (1996). Káñina. 31 (1), 139-143.

Sánchez-Corrales, V.M. (2008). Lexicografía y costarriqueñidad: el Diccionario de costarriqueñismos de Gagini (1918). Por C. Gagini. Diccionario de costarriqueñismos. (16-23). San José: Editorial Costa Rica.

Sánchez-Corrales, V.M. (2009). Ma(j)e. De la denotación a la apelación. Káñina. 33 (Especial), 33-43.

Sánchez-Corrales, V.M. (2010). Comunicación de masas y emigración léxica. Del cine clásico mexicano a la conformación de la costarriqueñidad. Káñina. 34 (Especial), 173-192. 
Sánchez-Corrales, V.M. (2011). ¡Puta! En el español de Costa Rica. A propósito de un procedimiento ordinario especial administrativo. Káñina. 35 (2), 83-86.

Sánchez-Corrales, V.M. (2012). Metáforas zoonímicas de humanos en el español de Costa Rica: Caballo, yegua/ burro, perro- perra, vaca y zorra. Estudio diferencial-contrastivo. Káñina. 36 (Especial), 27-36.

Sánchez-Corrales, V.M. (2013). Del Jeep Willys a la llave maya: marcas lexicalizadas en el español de Costa Rica. Káñina. 37 (1), 145-152.

Solano-Rojas, Y. (Comp.). (1994). Memoria del V Congreso de Filología y Lingüística "Prof. Arturo Agüero Chaves”. San José: Editorial Guayacán Centroamérica. 